\title{
Mortality risk factors during readmission at the Department of Medicine
}

This article was published in the following Dove Press journal:

Therapeutics and Clinical Risk Management

\section{Chayanis Trakulthong Anakapong Phunmanee}

Department of Medicine, Faculty of Medicine, Khon Kaen University, Khon Kaen, Thailand
Correspondence: Anakapong Phunmanee Department of Medicine, Faculty of Medicine, Khon Kaen University, 123 Mitraparp Road, Khon Kaen, 40002, Thailand

Tel +6643363664

Fax +66 3338399

Email anakapong@kku.ac.th
Background: Readmission is an indicator of quality of inpatient care. A study from Hong Kong found readmission mortality rate to be $5.1 \%$. There are limited reports on risk factors for mortality other than co-morbid diseases in readmission patients. This study, thus, aims to evaluate risk factors for mortality during readmission.

Methods: This study was conducted at a university hospital in Thailand. The inclusion criteria were patients aged $\geq 15$ years and readmission to internal medicine wards within 28 days after discharge. The outcome of the study was death during readmission. Risk factors for readmission mortality were analyzed using multivariate logistic regression analysis.

Results: There were 10,389 admissions to the Department of Medicine, Khon Kaen University, of which 407 required readmission (3.90\%). Of those patients, 75 (18.43\%) died during readmission. There were 6 independent factors associated with death in patients who were readmitted, including advanced age ( $>60$ years), presence of more than 2 co-morbid diseases, admission duration of $>14$ days, fever at previous discharge, low hemoglobin $(<12 \mathrm{~g} / \mathrm{dL})$, and having undergone over 5 procedures.

Conclusion: Older age, co-morbid diseases, readmission duration, presence of low hemoglobin at previous discharge, and numbers of procedures at readmission were significantly associated with increased mortality risk for readmission patients.

Keywords: readmission, mortality, predictors

\section{Introduction}

Readmission is an indicator of quality of inpatient care. ${ }^{1}$ In the USA, the readmission rate in 2009 was reported as $18 \%$, costing $>17$ billion USD/year. ${ }^{2}$ Hospitals with high readmission rates are liable to be fined by the Centers for Medicare and Medicaid Services. ${ }^{3}$ Readmission within 28-30 days after discharge is related to several factors, ${ }^{4-7}$ including chronic diseases, depression, and low body weight. Another study from Australia found that low hemoglobin $(<12 \mathrm{~g} / \mathrm{dL})$ or serum sodium $(<135 \mathrm{mEq} / \mathrm{L})$ at discharge were predictors for rehospitalization. ${ }^{5}$

A study from Hong Kong, in which the readmission rate was $16.7 \%$, reported the mortality rate of readmission patients to be $5.1 \%$. $^{7}$ The 3 leading causes of death in readmitted patients were cancer, heart disease, and cerebrovascular diseases. There are limited reports on the risk factors of death other than co-morbid diseases in readmission patients. This study aims to evaluate the risk factors for readmission mortality.

\section{Methods}

This study is a retrospective study conducted at Khon Kaen University's Srinagarind Hospital in Thailand. The inclusion criteria were patients aged $\geq 15$ years and readmission to the internal medicine wards within 28 days after discharge. We excluded patients 
admitted for radiotherapy, chemotherapy or other procedures identified by the International Classification of Diseases (ICD)-10 code Z51.0/51.1 and ICD-9 code 99.25. The study period was between January 1 and December 31, 2012.

Admission chart reviews of all eligible patients were performed. Data were collected, including baseline characteristics, principal diagnosis, co-morbid diseases, procedures, duration of admission, and treatment outcomes. The outcomes were defined as survival or death.

The patients were categorized by treatment outcome. Clinical factors were compared between the 2 groups using descriptive statistics and univariate logistic regression analyses. Those factors with $p$-values of $<0.25$ according to univariate logistic regression analysis were subjected to subsequent multivariate backward logistic regression analysis. A test for multicollinearity was also performed. The results were presented as unadjusted odds ratio, adjusted odds ratio, and 95\% CI.

\section{Sample size calculation}

On the basis of the results of a previous study, ${ }^{7}$ the estimated mortality rate for readmission patients was $8.9 \%$. With a deviation error of 0.03 and a CI of $95 \%$, the required sample size was 347.

Ethical approval was obtained from the Faculty of Medicine Ethics Committee, Khon Kaen University, which was instituted as per the Helsinki Declaration. The ethics committee waived the need to obtain patient consent in this retrospective study as the data collected by the researchers were de-identified.

\section{Results}

During the study period, there were 10,389 admissions to the Department of Medicine, Khon Kaen University, of which 407 required readmission (3.90\%). Of those patients, $75(18.43 \%)$ died during readmission. For patients who were readmitted, the median (first to third quartile ranges) ages of those who survived and those who died were 59 (45-71) and 67 (59-74) years, respectively. The median durations of previous admission of patients who survived and those who died were 6 (3-11) and 8 (4-15) days, respectively. However, the median durations of readmission of patients who survived and those who died were longer at 7 (4-14) and 14 (6-28) days, respectively. The top 5 co-morbid diseases (each patient could have more than one associated co-morbidity) were hypertension (147 patients), hypokalemia (109 patients), diabetes (105 patients), anemia of chronic disease ( 75 patients), and acute kidney injury (55 patients).
There were 10 factors associated with death in patients who were readmitted as assessed using univariate logistic regression analysis (Table 1). A higher proportion of patients who died were aged $>60$ years, had longer readmission durations, had dependent status, had 5 or more co-morbid diseases, and had undergone 5 or more procedures at readmission. The highest unadjusted odds ratio (95\% CI) for death was the presence of 5 or more co-morbid diseases at 7.44 (3.31-16.68).

There were 6 independent factors associated with death in patients who were readmitted, according to multivariate logistic regression analysis (Table 2). The highest adjusted odds ratio $(95 \% \mathrm{CI})$ for death was still the presence of 5 or more co-morbid diseases at readmission at 5.02 (2.11-11.90).

\section{Discussion}

The prevalence of readmission in this study was lower than that of previous studies. The readmission rate at the university hospital in this study was only $3.90 \%$ of the 10,389 total admissions. Studies from the USA and Australia had higher readmission rates at $22.3 \%$ and $38.7 \%$, respectively. ${ }^{4,5}$ The latter study showed such a high readmission rate due to the longer duration criteria. Unlike other studies, patients in that study were included if readmission occurred within 6 months. Co-morbid diseases are another important factor associated with readmission. ${ }^{8,9}$ The study from the USA mentioned earlier had a higher percentage of cancer patients (35.3\%) compared with this study $(14.50 \%)$. Finally, as our hospital is a teaching hospital, when there were no available beds the readmission patients were referred to a nearby tertiary services hospital. Due to the limitations of this study being retrospective in nature, there were no data available on these patients.

The study from Hong Kong mentioned earlier found the mortality rate of readmission patients to be $5.1 \%,{ }^{7}$ which was lower than in this study $(18.43 \%)$. These findings may indicate better healthcare in Hong Kong than in Thailand. Once again, another factor that affects mortality rate is co-morbid disease. Cancer patients had an extremely high mortality rate at $30.8 \%$. $^{7}$ Similarly, patients with $>5$ co-morbid diseases had 5 times greater risk of mortality, or an $\sim 100 \%$ increase in mortality rate for each co-morbid disease over one (Table 2).

Several factors have been reported to be associated with readmission risks such as low hemoglobin $(<12 \mathrm{~g} / \mathrm{dL})$, length of stay ( $>5$ days), or having undergone any medical procedures. ${ }^{5}$ In this study, we found that these factors were 
Table I Factors associated with death after readmission according to univariate logistic regression analysis

\begin{tabular}{|c|c|c|c|c|c|}
\hline Factors & $\begin{array}{l}\text { Survived, } \\
n=332\end{array}$ & $\begin{array}{l}\text { Died, } \\
n=75\end{array}$ & OR & $95 \% \mathrm{Cl}$ & p-value \\
\hline Male patients & 191 (57.53) & $46(61.33)$ & 1.17 & $0.70-1.95$ & 0.54 \\
\hline Age $>60$ years & $161(48.49)$ & $56(74.67)$ & 3.14 & I.78-5.49 & $<0.001$ \\
\hline Previous admission $\geq 14$ days & $56(16.88)$ & $20(20.67)$ & 1.79 & $0.99-3.22$ & 0.05 \\
\hline Readmission $\geq 14$ days & $75(66.96)$ & $37(33.04)$ & 3.33 & $1.98-5.6 \mid$ & $<0.001$ \\
\hline Previous number of admissions in the past year ${ }^{a}$ & $2(2-3)$ & $2(2-3)$ & 1.09 & $0.96-1.23$ & 0.17 \\
\hline Fever at previous discharge & $38(11.45)$ & $15(20.00)$ & 1.93 & $1.00-3.73$ & 0.05 \\
\hline Hemoglobin $<12 \mathrm{~g} / \mathrm{dL}$ at previous discharge & $51(15.36)$ & $6(8.00)$ & 0.47 & $0.19-1.10$ & 0.10 \\
\hline Nursing home stay & $12(3.6 I)$ & $6(8.00)$ & 2.31 & $0.84-6.39$ & 0.10 \\
\hline No caregiver & I $(0.30)$ & I (I.33) & 4.47 & $0.27-72.33$ & 0.29 \\
\hline Dependent status & $40(12.05)$ & $15(20.00)$ & 2.35 & $1.15-4.79$ & 0.01 \\
\hline Co-morbid diseases $>5$ & $163(49.10)$ & $52(69.33)$ & 2.34 & $1.37-4.0$ & 0.002 \\
\hline Co-morbid diseases $>5^{b}$ & $188(56.63)$ & $68(90.67)$ & 7.44 & $3.31-16.68$ & $<0.001$ \\
\hline No of procedures $>5$ & $48(14.46)$ & $14(18.67)$ & 1.35 & $0.70-2.61$ & 0.36 \\
\hline No of procedures $>5^{b}$ & $258(77.7 I)$ & $72(96.00)$ & 6.88 & 2. $10-22.48$ & 0.001 \\
\hline CKD & $56(16.87)$ & $3(4.00)$ & 0.20 & $0.06-0.67$ & 0.009 \\
\hline Cancer & $40(12.05)$ & $19(25.33)$ & 2.47 & $1.33-4.57$ & 0.004 \\
\hline Hematologic malignancy & $32(9.64)$ & $7(9.33)$ & 0.96 & $0.40-2.27$ & 0.93 \\
\hline Pneumonia, COPD & $20(6.02)$ & $10(13.33)$ & 2.40 & $1.07-5.36$ & 0.03 \\
\hline Rheumatic diseases & $14(4.22)$ & $2(2.67)$ & 0.62 & $0.13-2.97$ & 0.53 \\
\hline $\mathrm{CKD}^{\mathrm{b}}$ & $45(13.55)$ & $\mathrm{I}(\mathrm{I} .33)$ & 0.08 & $0.10-0.63$ & 0.01 \\
\hline Cancer $^{\mathrm{b}}$ & $42(12.65)$ & $16(21.33)$ & 1.87 & $0.98-3.55$ & 0.055 \\
\hline Hematologic malignancy ${ }^{\mathrm{b}}$ & $35(10.54)$ & $7(9.33)$ & 0.87 & $0.37-2.05$ & 0.75 \\
\hline Pneumonia, COPD ${ }^{\mathrm{b}}$ & $25(7.53)$ & II (I4.67) & 2.11 & $0.98-4.50$ & 0.05 \\
\hline Rheumatic diseases $^{b}$ & $14(4.22)$ & $2(2.67)$ & 0.62 & $0.13-2.97$ & 0.53 \\
\hline
\end{tabular}

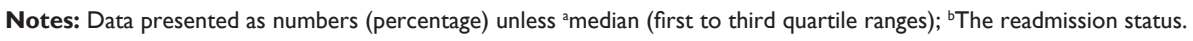

Abbreviations: CKD, chronic kidney disease; OR, odds ratio.

indicators for death after readmission (Table 2). Mortality risk was higher by 3.91 times if $>5$ procedures had been performed, and a readmission stay of $>14$ days increased the risk of death by $93 \%$.

Elderly patients are especially at risk for readmission and death during readmission. ${ }^{7,10,11}$ A previous study showed that age $>75$ years was associated with readmission and mortality. ${ }^{7}$ This study found that physicians should be aware of the 2.43 times higher mortality risk in patients

Table 2 Factors associated with death after readmission according to multivariate logistic regression analysis

\begin{tabular}{llll}
\hline Factors & $\begin{array}{l}\text { Adjusted } \\
\text { OR }\end{array}$ & $\mathbf{9 5 \%} \mathbf{C l}$ & p-value \\
\hline Age $>60$ years & 2.43 & $1.31-4.48$ & 0.004 \\
Co-morbid diseases $>5^{\mathrm{a}}$ & 5.02 & $2.1 \mathrm{I}-\mathrm{II} .90$ & $<0.00 \mathrm{I}$ \\
Admission duration $\geq \mathrm{I} 4$ days $^{\mathrm{a}}$ & $\mathrm{I} .93$ & $\mathrm{I} .08-3.43$ & 0.02 \\
Fever at previous discharge & 2.35 & $\mathrm{I} .10-4.99$ & 0.02 \\
Hemoglobin $<12$ g/dL at & 0.35 & $0.13-0.92$ & 0.03 \\
previous discharge & & & \\
No caregiver & 14.6 & $0.83-255.04$ & 0.06 \\
Procedure $>5^{\mathrm{a}}$ & $3.9 \mathrm{I}$ & $\mathrm{I} .13-13.49$ & 0.03 \\
\hline
\end{tabular}

Note: ${ }^{\text {Readmission status. }}$

Abbreviation: OR, odds ratio. aged $>60$ years (Table 2 ). The presence of fever at previous discharge also increased mortality risk, as has previously been reported..$^{10,11}$

There are some limitations to this study. The criteria for readmission in this study was 28 days, and not 30 like other reports from the USA, Hong Kong, and Australia. Readmission within 28 days after discharge is the criterion used by most hospitals in Thailand. ${ }^{12}$ However, this factor may not have a large effect on the results. Second, the results of this study may not be universal due to different standards of healthcare, common diseases, and co-morbid diseases in various countries. This information may be used to stratify patients and improve local care when physicians and hospital staff have high workloads in order to determine who can be safely discharged and who cannot.

\section{Conclusion}

Older age, co-morbid diseases, readmission duration, presence of fever or low hemoglobin at previous discharge, and number of procedures at readmission were significantly associated with increased mortality risk for patients who were readmitted. 


\section{Disclosure}

The authors report no conflicts of interest in this work.

\section{References}

1. Ashton CM, Del Junco DJ, Souchek J, Wray NP, Mansyur CL. The association between the quality of inpatient care and early readmission: a meta-analysis of the evidence. Med Care. 1997;35(10):1044-1059.

2. Jencks SF, Williams MV, Coleman EA. Rehospitalizations among patients in the Medicare fee-for-service program. N Eng J Med. 2009; 360(14):1418-1428.

3. Gpo.gov. Washington DC: Public Protection and Affordable Care Act, Pub L No 111-148, Section 3025: Hospital readmissions and reduction program; 124 STAT. 408. March 23, 2010. Available from: https://www. gpo.gov. Accessed March 15, 2016.

4. Mudge AM, Kasper K, Clair A, et al. Recurrent readmissions in medical patients: a prospective study. J Hosp Med. 2011;6(2):61-67.

5. Donzé J, Aujesky D, Williams D, Schnipper JL. Potentially avoidable 30-day hospital readmissions in medical patients: derivation and validation of a prediction model. JAMA Intern Med. 2013;173(8):632-638.
6. Yam CH, Wong EL, Chan FW, et al. Avoidable readmission in Hong Kong-system, clinician, patient or social factor? BMC Health Serv Res. 2010;10:311.

7. Wong EL, Cheung AW, Leung MC, et al. Unplanned readmission rates, length of hospital stay, mortality, and medical costs of ten common medical conditions: a retrospective analysis of Hong Kong hospital data. BMC Health Serv Res. 2011;11:149.

8. Vipperla K, Papachristou GI, Easler J, et al. Risk of and factors associated with readmission after a sentinel attack of acute pancreatitis. Clin Gastroenterol Hepatol. 2014;12(11):1911-1919.

9. Shah SV, Corado C, Bergman D, et al. Impact of poststroke medical complications on 30-day readmission rate. J Stroke Cerebrovasc Dis. 2015;24(9):1969-1977.

10. Gautam P, Macduff C, Brown I, Squair J. Unplanned readmissions of elderly patients. Health Bull (Edinb). 1996;54(6):449-457.

11. Rosenberg AL, Watts C. Patients readmitted to ICUs*: a systematic review of risk factors and outcomes. Chest. 2000;118(2):492-502.

12. Kerdsin S, Suphanchaimat R. Outcome of service development program on within 28 days readmission of chronic obstructive pulmonary disease (COPD) patients: a case study of Somdejphrajaotaksinmaharaj Hospital, Tak Province. J Health Sci. 2016;25:246-254.
Therapeutics and Clinical Risk Management

\section{Publish your work in this journal}

Therapeutics and Clinical Risk Management is an international, peerreviewed journal of clinical therapeutics and risk management, focusing on concise rapid reporting of clinical studies in all therapeutic areas, outcomes, safety, and programs for the effective, safe, and sustained use of medicines. This journal is indexed on PubMed Central, CAS,

\section{Dovepress}

EMBase, Scopus and the Elsevier Bibliographic databases. The manuscript management system is completely online and includes a very quick and fair peer-review system, which is all easy to use. Visit $\mathrm{http}: / /$ www.dovepress.com/testimonials.php to read real quotes from published authors. 